\title{
HOMENAGEM: JK, O HOMEM, O PRESIDENTE, A ATUALIDADE ${ }^{1}$
}

\author{
A TRIBUTE TO "JK": THE MAN, THE PRESIDENT, THE PRESENT
}

Celso Lafer*

\begin{abstract}
Resumo:
O sucesso do governo JK está ligado à qualidade do seu juízo político, que lhe permitiu promover o desenvolvimento econômico com estabilidade política democrática, lastreado numa tolerância liberal que levou a bom termo a meta da legalidade democrática. Ele criou o novo a partir do existente, em sintonia com as polaridades da sua personalidade: um homem de ação, preocupado em fazer coisas e, ao mesmo tempo, um bem-sucedido exemplo de planejador; um homem moderno com apego a tradições; um cosmopolita com aspectos provincianos; um intuitivo com a capacidade do diagnóstico a partir da experiência de médico. Ele mudou o país com imaginação política, imaginação administrativa, talento, liderança, criatividade.
\end{abstract}

Palavras-chave: Homenagem. Juscelino Kubitschek de Oliveira. Presidência da República (1956-1961). Programa de Metas.

\begin{abstract}
:
JK government's success is due to the great quality of his political insights, which allowed him to promote economic development along with democratic political stability, hedged by a liberal tolerance that allowed him to achieve his goals of democratic legitimacy. He created the newness from what already existed, welltuned with the characteristics of his personality: he was a man of action, concerned with doing things, and at the same time a successful public planner; he was a modern man with a penchant for traditions, a cosmopolitan with small town peculiarities; an intuitive with diagnosis capacity that came together with his experience as a physician. He changed the country with political imagination, management imagination, talent, leadership, creativity.
\end{abstract}

Keywords: Tribute. Juscelino Kubitschek de Oliveira. President of the Republic (1956-1961). Plan of Goals.

Eu gostaria de, em primeiro lugar, cumprimentar o Professor Alessandro Serafim Octaviani Luis e a iniciativa do grupo Direito e Subdesenvolvimento que enfrentaram os desafios para organizar, aqui na Faculdade, esse evento, justamente no dia do aniversário do Presidente Juscelino. Eu tenho muita satisfação de poder ver entre os que estão presentes o João César e a Júlia, que representam a continuidade familiar do legado do Presidente Juscelino. É um prazer estar ao lado da Rosa Freire d'Aguiar

\footnotetext{
Versão revista da exposição feita em 12 de setembro de 2013 na Faculdade de Direito da USP, na sala da Congregação, em evento organizado pelo Grupo Direito e Subdesenvolvimento da Faculdade.

* Professor Emérito da Faculdade de Direito da Universidade de São Paulo.
} 
Furtado, que conhece tão bem esse período, e que tem um notável trabalho na divulgação, registro, e reflexão sobre o legado de um grande homem que foi Celso Furtado. Como ela diz, com toda a razão, foi no governo do Presidente Juscelino que ele teve a oportunidade de exercer relevante função pública e, ao exercê-la, contribuir de uma maneira efetiva para o desenvolvimento do nosso país.

Devo dizer que tenho na plateia o meu amigo Ronaldo Costa Couto, grande biógrafo do presidente, grande conhecedor deste período. É uma alegria ter aqui a oportunidade de rever o Carlos Murilo, uma pessoa tão ligada ao Presidente Juscelino e que integrava um grupo formidável que se dedicou à celebração de seu centenário. Eu participei desse grupo e era uma admirável oportunidade de discutir o significado da sua obra. Também quero cumprimentar Jean Claude Obry, que está se dedicando ao trabalho de coordenar o Projeto JK.

Devo dizer que eu posso falar com satisfação sobre o Presidente Juscelino, porque estudei a obra dele e tive o privilégio de conhecê-lo pessoalmente, pois a minha tese de doutoramento sobre o Programa de Metas teve como um dos seus ingredientes importantes o lastro das múltiplas entrevistas que eu fiz com o próprio Presidente, inclusive no período mais difícil de sua vida, que foi o período do exílio. Eu tenho, por isso mesmo, muita alegria nesta oportunidade, de falar de um grande homem que me honrou com sua amizade.

Eu procurei estruturar um pouco a minha exposição, e o primeiro aspecto que eu gostaria de mencionar é o capítulo da liderança política e das suas características. Vou começar pelo geral para chegar ao específico. Um grande estudioso francês diz que toda grande liderança política tem dois componentes. O componente Dux que inova, transforma e por isso frequentemente desestabiliza, e o componente Rex que pacifica, harmoniza e por vezes imobiliza. Todo líder bem-sucedido combina de maneira própria essas duas características. Um exemplo no Brasil é o caso de Getúlio Vargas. Em toda política autêntica, e é por isso que esses componentes são importantes, postula-se a união dos contrários. Ou seja, são necessários ao mesmo tempo um impulso e um freio, uma força de aceleração de mudança social e uma força de contenção que impeça a vertiginosidade.

É importante ver como um líder político bem-sucedido combina essas duas dimensões para assegurar a estabilidade política, que é um dos temas da nossa exposição. E naturalmente todo líder político tem a estratégia condizente com sua personalidade. Diz o Padre Antônio Vieira que quando Davi subiu a montanha para enfrentar o gigante Golias, Saul ofereceu-lhe suas armas e Davi as recusou. A conclusão do Padre Vieira é que as armas de Saul servem a Saul, as armas de Davi servem a Davi. Quais foram as armas com as quais o Presidente Juscelino construiu sua admirável liderança?

Eu creio que cabe aqui acrescentar outra observação sobre a importância do juízo político. O juízo político é a capacidade de perceber e de identificar as características 
próprias de um contexto. É uma sabedoria prática. É a avaliação do que funciona e do que não funciona. É um senso da realidade. E o juízo político é algo distinto do pensar e do querer. É um juízo reflexivo que extrai da conjuntura e do seu particular o seu sentido geral. $\mathrm{O}$ sucesso do governo do Presidente Juscelino está ligado à qualidade do seu juízo político que lhe permitiu promover o desenvolvimento econômico com estabilidade política democrática, lastreado numa tolerância liberal que levou a bom termo a meta da legalidade democrática.

Eu escrevi a minha tese em 1970, um período difícil da preponderância do arbítrio do nosso país. O que me fascinou naquele contexto e o que me levou a querer escrever sobre Juscelino foi o modo como ele conseguiu ao mesmo tempo promover o desenvolvimento e assegurar a estabilidade democrática. Queria entender a forma que ele encontrou para lidar com um desafio extraordinário, que é combinar o desenvolvimento econômico com o desenvolvimento político-democrático no Brasil da sua época. Pois bem, eu creio, sintetizando, que o modo foi o de criar o novo a partir do existente, em sintonia com as polaridades da sua personalidade. O Presidente Juscelino era um homem de ação, preocupado em fazer coisas. É essa história que foi mencionada de cobrar às oito da manhã, às cinco da manhã, às seis da manhã, providências que eram fundamentais para levar adiante o seu sentido de ação. Daí uma dimensão que ele tinha não só de "tocador" de coisas, mas de improvisador. Por outro lado, ele foi ao mesmo tempo um bem-sucedido exemplo de planejador. Ele combinou as duas coisas, o que não é fácil. Era uma pessoa com vocação para ação, capaz de improvisar, mas foi um bem-sucedido planejador, porque o Plano de Metas foi a primeira tentativa bem-sucedida de planejamento no Brasil.

Claro que ele se baseou, em primeiro lugar, na sua própria experiência como governador de Minas Gerais, com o binômio energia e transportes. E naturalmente com base nessa experiência, ele enquanto Presidente da República levou adiante uma tentativa muito mais abrangente, que foi o Programa de Metas. A base da minha tese consiste em explicar como que ele levou adiante o programa de metas, porque ele decidiu planejar e como ele foi bem-sucedido na operacionalização do planejamento. Mexer com a máquina estatal, falo eu com experiência própria, não é uma coisa simples. E eu acho admirável como ele conseguiu lidar com esse desafio nas condições do país na época em que ele foi Presidente. Era ao mesmo tempo o planejador e o improvisador. Ele era um homem moderno. Apreciou a arquitetura de Niemeyer, deu espaço para a pintura de Portinari, foi o primeiro presidente a administrar com o avião, e também o primeiro a se comunicar com a sociedade por meio da televisão.

Para os jovens isso pode parecer uma coisa da Idade da Pedra. Mas evidentemente nos anos 1950, administrar através da presença pelo país como um todo e se valer da televisão como um meio de comunicação de larga escala eram atributos excepcionais. Por outro lado, ele tinha uma dimensão tradicional. Primeira observação é 
que a carreira política dele obedeceu às cadências tradicionais. Ele foi deputado, ele foi prefeito, ele foi constituinte, ele foi governador. Contrasta, por exemplo, com a postura de ruptura que caracterizou Jânio Quadros e Fernando Collor.

Juscelino tinha uma dimensão cosmopolita e uma dimensão provinciana. Ele foi um homem atento ao mundo. Nos anos 1930, e depois de se formar em medicina, ele foi estudar em Paris. Fez uma viagem pela Europa e pelo Oriente. Nos anos 1940, ele fez uma viagem ao Canadá e aos Estados Unidos, e se deu conta da importância da industrialização. Portanto, a primeira observação é que ele não tinha medo do mundo. $\mathrm{O}$ mundo não o assustava. Por outro lado, ele era um homem de raízes profundas. Diamantina tinha uma dimensão muito importante na vida dele. E ele só se sentia um peixe dentro da água no Brasil, por isso que o exílio foi tão terrível para ele. Isso fez com que ao mesmo tempo ele se valesse do capital estrangeiro para promover a substituição de importações e fosse um nacionalista, porém um nacionalista sem xenofobia. Foi capaz de romper, por exemplo, com o FMI, quando isso lhe pareceu fundamental para não obstaculizar o desenvolvimento do Programa de Metas.

Ele era um intuitivo. Com base na sua experiência de médico, ele tinha a experiência do diagnóstico. O diagnóstico para o médico é como um juízo político para um homem público. E ele sabia aplicar essa experiência do diagnóstico na avaliação das coisas. Daí, por exemplo, um ponto básico da sua candidatura presidencial. "O Brasil não é um país agrícola por vocação hereditária" dizia, transmitindo a ideia que o Brasil tinha outras possibilidades. Daí sua afirmação que estão "querendo aplicar a um país jovem, os remédios da velhice". A metáfora é a de um médico, mas correspondia ao juízo político apropriado sobre o que fazer. Ele sempre reconheceu a importância do racional e do conhecimento profissional do saber técnico. A Rosa acabou de mencionar como ele apostou e confiou no Celso Furtado, que era um jovem, quando entendeu, conversando com ele, o significado daquilo que ele estava trazendo como uma mensagem de inovação. Então ele juntou pessoas altamente qualificadas. Lucas Lopes teve um papel muito importante, como integrante da Comissão Mista Brasil-Estados Unidos e em função da experiência da CEMIG em Minas Gerais. Um ponto de partida de Lucas Lopes foi a geografia econômica. A compreensão da dimensão da especificidade do país e da sua geografia ajudou na compreensão dos problemas de infraestrutura que o Programa de Metas procurou equacionar.

É indiscutível o saber jurídico e de organização que caracterizava o Vitor Nunes Leal na Casa Civil. Pessoas com grande talento executivo, como o Lúcio Meira, de saber político como Amaral Peixoto e, para os que gostam de Direito Econômico, cabe mencionar que no âmbito do BNDE Bulhões Pedreira teve um grande papel como advogado, encontrando uma série de soluções jurídicas apropriadas para lidar com aquilo que veio a ser o Programa de Metas. O Presidente Juscelino tinha a gravitas de 
um estadista quando a situação exigia. É sua aquela frase fantástica: "Deus me poupou o sentimento do medo", uma expressão da firmeza. A coragem política é indispensável para quem exerce a vida pública. E, sem dúvida nenhuma, coragem política nunca faltou ao Presidente Juscelino, ele tinha esse sentimento das suas próprias forças, que era uma dimensão do otimismo que a Rosa mencionou. E ao mesmo tempo, ele era uma pessoa alegre com gosto pela vida. E é por isso que ele combinava tudo aquilo que era necessário para captar a sensibilidade popular. Era bem capaz de liderar ao mesmo tempo capaz de sentir e de conviver. E ele era, sobretudo uma personalidade generosa, sem ressentimentos e sem ódios. São exemplos as duas anistias em relação aos que se opuseram, pelas armas, ao seu governo. E aqui eu vou contar um episódio.

No centenário do Presidente, as ruas de Brasília e os prédios de Brasília tinham imensos cartazes com a figura do Juscelino. Pois bem, nessa ocasião veio ao Brasil o Presidente Hugo Chávez, para agradecer o Presidente Fernando Henrique Cardoso pela defesa que o Brasil fez do seu mandato e a luta diplomática bem-sucedida contra um golpe de Estado que se tentou contra ele. Chávez, que era uma pessoa de boa conversa, chegou ao automóvel e disse: “Quem é esse senhor?" FHC respondeu: "É um homem extraordinário, foi um grande Presidente do Brasil, fez um programa de desenvolvimento extraordinário, era um homem de grande tolerância liberal, tanto que anistiou todos aqueles que pelas armas se opuseram a ele. E se eu fosse você, faria a mesma coisa para lidar com o tema da estabilidade política na Venezuela." É uma história divertida que eu acho que vale a pena contar.

Eu construí minha tese seguindo uma reflexão do Hélio Jaguaribe, grande nome da nossa ciência política, muito amigo do Celso Furtado e sucessor dele na Academia Brasileira, de certo modo por indicação do próprio Furtado. Jaguaribe dizia que para analisar um sistema político, é preciso fazer uma análise das variáveis de participação - a participação da sociedade no sistema político -, das variáveis operacionais - como se processam demandas -, e das variáveis de direção - para onde vai o sistema por obra do seu funcionamento. Pois bem, do ponto de vista das variáveis de participação, esta foi a minha linha de argumentação e estava se verificando uma ampliação do voto e da cidadania, ou seja, a eleição de JK significou uma participação maior do povo na vida política brasileira. JK interpretou-a no plano político como uma responsabilidade com a democracia. E no plano econômico, no aumento do nível geral da vida, através da expansão das possibilidades de consumo e de emprego.

Bom, de que modo Juscelino levou isto adiante? Quer dizer, como é que ele criou o novo a partir do existente? Essa é uma tarefa muito complicada, porque se você fica no existente, você imobiliza. Se você inova, você precisa inovar levando em conta o sentido da realidade. No plano político, ele fez isso através da imaginação com a qual ele construiu a aliança PSD e PTB, que eram dois grandes partidos da vida brasileira daquele 
período. O PTB com uma dimensão de maior participação popular e de maior vocação para mudança e inovação, e o PSD como um partido mais tradicional, mas não como um partido indiferente à mudança e à sua importância.

O Amaral Peixoto, que foi presidente do PSD, dizia: "Eu sou um homem do centro. E um homem do centro para se manter no centro tem que caminhar para esquerda." A aliança PSD-PTB foi fruto desta combinação. Foi o Presidente Juscelino que teve a imaginação política de fazer com que essa aliança funcionasse de maneira inovadora. Convém não esquecer que o Programa de Metas era um plano setorial, o que significou que havia ainda recursos dentro do orçamento que permitiam as acomodações políticas necessárias.

No plano operacional, eu creio que vale a pena salientar a imaginação administrativa a partir da qual a racionalidade superior veio daquilo que existia. Em primeiro lugar, vem a pergunta, como é que foi formulado o Programa de Metas? Em 1950 não tinha computador, as estatísticas eram fracas, por isso fazer um programa com a qualidade que teve o Programa de Metas não era uma coisa simples. Ele foi um plano que envolvia energia, transportes, alimentação, indústrias de base e educação. O que fez o Programa de Metas? No seu momento inicial, baseou-se em estudos anteriores, como os realizados pela Comissão Mista Brasil-Estados Unidos, elaborados no início da década de 1950, no governo do Presidente Getúlio Vargas, e é daí que surge o BNDE. Além disso, havia no âmbito do BNDE um grupo misto CEPAL-BNDE, do qual o Celso Furtado participou, que refinou, com visão geral, os projetos da Comissão Mista.

O Programa de Metas tinha dois conceitos importantes. A ideia dos pontos de estrangulamento e dos pontos de germinação. Os primeiros eram os gargalos que emperravam a economia do país, como os meios de transporte e a escassez do câmbio. Os segundos residiam na ideia de que se lidasse com os pontos de estrangulamento, condições de germinação seriam criadas para a expansão da economia brasileira. $\mathrm{O}$ processo deliberado de substituição de importações é fruto da percepção dos elos da cadeia produtiva.

Como pôr em funcionamento um programa com aquela amplitude, levando em conta as características da Administração Pública do Brasil naquele momento? JK teve uma extraordinária imaginação criadora, porque ele no fundo operou por meio de uma “administração paralela". Essa administração paralela era constituída por órgãos que controlavam as zonas de incerteza indispensáveis para viabilizar as metas. E, desta forma, concedia ou não os incentivos, ou moldava ou desincentivava os grandes projetos. Esses órgãos como, por exemplo, os grupos executivos da qual o mais conhecido era o GEIA, da indústria automobilística, e a CACEX, que administrava as importações. Havia também a SUMOC, que lidava com os recursos que poderiam ser postos à disposição e a Carteira de Câmbio. Para esses órgãos foram canalizados as competências e os poderes 
necessários que direcionaram os investimentos públicos e privados através da liberação dos fundos vinculados do orçamento, dos estímulos fiscais, das licenças de importação e de câmbio, na medida em que as propostas e projetos públicos e privados se enquadravam no contexto dos objetivos governamentais. No que tange ao tema da administração paralela, foi através da operação dessas instâncias que JK procurou lidar com problemas que considerava fundamentais.

No caso de Brasília, houve a implantação da nova capital, ideia que estava ligada ao tema da interiorização do país. É um tema conhecido, importante e recorrente na história do Brasil, como no caso de Minas Gerais, pela experiência da criação de uma nova capital, Belo Horizonte. Daí a criação da nova capital e a confiança que Juscelino teve em Israel Pinheiro, que levou adiante a construção, por meio da NOVACAP, também uma instância de administração paralela. Da mesma maneira, a SUDENE mencionada por Rosa, configurou um esforço importante para lidar com as disparidades regionais e com o desequilíbrio federativo, sem mais se basear na "solução" tradicional, que era a construção de açudes. Compreendeu que o problema do Nordeste não era um problema de água, mas um problema econômico de outra abrangência. E confiou com toda razão essa tarefa a Celso Furtado, o qual foi capaz de lidar, com o apoio do Presidente, com resistências a um processo de mudança, alguma das quais a Rosa relatou em seu depoimento.

Um exemplo de inovação em matéria diplomática é a Operação Panamericana, que foi um esforço extraordinário. Primeiro, foi uma grande operação de diplomacia presidencial, à maneira de Juscelino, tendo um grupo de assessores, entre eles Augusto Frederico Schmidt, que quiseram empreender essa inovação e que sentiam que se fossem se valer apenas dos órgãos tradicionais, como era o caso do Itamaraty, não haveria uma operação com essa envergadura. Naturalmente, para puxar a brasa para minha sardinha, quem implementou a Operação Pan-americana, por meio do Itamaraty, foi Horácio Lafer, o último chanceler do governo de Juscelino.

Do ponto de vista das variáveis de direção, ele se propôs a fazer 50 anos em 5 e ele fez 50 anos em 5 . E eu concluo com uma observação que faz Joaquim Nabuco em um livro muito interessante, chamado Balmaceda, que termina dizendo: "Como é que se avalia um chefe de Estado?" Ele responde: "Avalia-se um chefe de Estado não apenas pelas suas qualidades pessoais, mas pelo inventário nacional. Como ele encontrou o país e como ele deixou o país." É evidente que se nós olharmos o inventário do nosso país antes da entrada do presidente Juscelino no Poder e depois, ele mudou o país. E mudou o país com imaginação política, com imaginação administrativa, com talento, com liderança, com criatividade.

Houve uma minissérie muito interessante sobre o presidente Juscelino. Ronaldo Costa Couto foi um dos que colaborou também na documentação necessária para a Maria Adelaide Amaral, que foi quem fez o roteiro básico. E conversando com ela, 
eu dizia o seguinte: “O governo do Presidente Juscelino não foi um governo fácil. Nós falamos nos 'anos dourados', mas ele enfrentou oposição cerrada. E ele soube lidar com essa oposição com grande tolerância." No entanto, na medida em que os anos passaram, ele cresceu no imaginário político brasileiro. Cresceu no imaginário político como uma das grandes figuras do país. E cresceu por essas qualidades que eu procurei sucintamente descrever. Essa generosidade, essa imaginação, essa capacidade de liderança. Quem teve o privilégio de conhecer o Presidente Juscelino se dava conta de uma característica da própria maneira de ser dele: se ele entrasse nessa sala e fosse falar agora, vocês veriam uma pessoa simples, fácil e acessível, mas, ao mesmo tempo, com um grande sentido de autoridade daquilo que fez e daquilo que ele estava fazendo. A simplicidade não tolhia a percepção da grandeza do personagem que ele foi.

O Padre Antônio Vieira dizia que a verdade é a aspiração da história. E a verdade é dificultosa. Falando sobre a verdade, ele dizia que todas as penas nasceram em carne e sangue, e todas na tinta de escrever, misturaram as cores do seu afeto. Eu sei que, ao falar do Presidente, as cores do meu afeto estão presentes. Mas eu sei que eu não faço uma injustiça em relação à verdade histórica ao descrevê-lo como procurei fazer para vocês agora. Obrigado.

São Paulo, junho de 2014. 